\title{
Employing LFPs and spikes to model the non-linear behavior of the STN
}

\author{
Kostis P Michmizos*1, Georgios L Tagaris ${ }^{2}$, Damianos E Sakas ${ }^{3}$ and \\ Konstantina S Nikita ${ }^{1}$
}

\author{
Address: ${ }^{1}$ National Technical University of Athens, Athens, Greece, ${ }^{2} \mathrm{G}$. Genimatas General Hospital, Athens, Greece and ${ }^{3}$ Department of \\ Neurosurgery, National and Kapodistrian University of Athens, Athens, Greece \\ Email: Kostis P Michmizos* - konmic@biosim.ntua.gr \\ * Corresponding author
}

from Eighteenth Annual Computational Neuroscience Meeting: CNS*2009

Berlin, Germany. 18-23 July 2009

Published: 13 July 2009

BMC Neuroscience 2009, I0(Suppl I):P320 doi:10.1186/I47|-2202-I0-SI-P320

This abstract is available from: http://www.biomedcentral.com/I47/-2202/I0/SI/P320

(C) 2009 Michmizos et al; licensee BioMed Central Ltd.

The subthalamic nucleus (STN) is a pivotal point of the basal ganglia (BG) function and dysfunction [1]. Its crucial engagement with the neurosurgical procedure of deep brain stimulation (DBS) that alleviates medically intractable Parkinsonian tremor [2] augments the need to refine our current understanding of it. In the STN of monkeys and humans, there is a progressive bending of the dendrites along the nuclear limits. In this way, the STN becomes a closed nucleus that receives and processes only afferents that are specifically devoted to it [3]. For this reason, it represents a target that is perfectly delimited, both anatomically and functionally. The subsequent analysis focuses on spontaneous STN activity, defined as the neuronal activity during periods in which the patient is immobile.

Raw intranuclear microelectrode recordings (MERs), received from Parkinsonian patients during surgery, are lowpass filtered to acquire local field potentials (LFPs) and highpass filtered to receive the spiking activity of the cells inside the nucleus. Under the physiologically justified assumption that the LFPs constitute the input of the cells inside the nucleus [4] whereas the spikes are the output [5], the STN cells are regarded as a black box and an input output system analysis of the STN is straightforward. A nonlinear approach for modeling the system is selected after trial and error experiments. Results show that a non-linear Hammerstein-Wiener model is able to simulate the STN output with a reasonable accuracy. We estimate the components of the model and use a comparison between the predicted and observed spikes as well as the consistency of the obtained model for different recordings to validate the quality of the prediction. By applying the Lilliefors' test, we ensure that a model having an adequate \% fit and being able to simulate the neuronal spikes with at least good temporal accuracy also has residuals with roughly normal distribution.

Given the central position of the STN, influencing both primary basal ganglia output nuclei in an excitatory fashion, the approach of input output modeling may serve as the testing bed for the several theories been proposed. Finding the actual role of the STN in both normal and pathological conditions, underscores the potential of recording the LFPs with deep-brain electrodes and using them as feedback signals to improve the therapeutic effect of deep-brain-stimulators.

\section{References}

I. The Deep-Brain Stimulation for Parkinson's Disease Study Group: Deep-brain stimulation of the subthalamic nucleus or the pars interna of the globus pallidus in Parkinson's disease. $N$ Engl J Med 200I, 345:956-63.

2. Just $H$, Ostergaard $\mathrm{K}$ : Health-related quality of life in patients with advanced Parkinson's disease treated with deep brain stimulation of the subthalamic nuclei. Mov Disord 2002, I 7:539-545.

3. Hammond C, Yelnik J: Intracellular labelling of rat subthalamic neurones with horseradish peroxidase: computer analysis of 
dendrites and characterization of axon arborization. Neuroscience 1983, 8:78I-790.

4. Bedard C, Kroger H, Destexhe A: Modeling extracellular field potentials and the frequency-filtering properties of extracellular space. Biophys J 1986, 204: 1829-1842.

5. Dayhoff JE, Gerstein GL: Favored patterns in spike trains: II. Appl J Neurophysiol 1983, 49:1349-I 363.

Publish with Bio Med Central and every scientist can read your work free of charge

"BioMed Central will be the most significant development for disseminating the results of biomedical research in our lifetime. " Sir Paul Nurse, Cancer Research UK

Your research papers will be:

- available free of charge to the entire biomedical community

- peer reviewed and published immediately upon acceptance

- cited in PubMed and archived on PubMed Central

- yours - you keep the copyright

Submit your manuscript here:

http://www.biomedcentral.com/info/publishing_adv.asp 